\title{
Review Article \\ Biological Pathways and Potential Targets for Prevention and Therapy of Chronic Allograft Nephropathy
}

\author{
Badri Man Shrestha and John Haylor \\ Division of Renal Transplantation, Sheffield Kidney Institute, Northern General Hospital, Herries Road, Sheffield S5 7AU, UK \\ Correspondence should be addressed to Badri Man Shrestha; shresthabm@doctors.net.uk
}

Received 12 February 2014; Accepted 4 May 2014; Published 27 May 2014

Academic Editor: Paul J. Higgins

Copyright ( 2014 B. M. Shrestha and J. Haylor. This is an open access article distributed under the Creative Commons Attribution License, which permits unrestricted use, distribution, and reproduction in any medium, provided the original work is properly cited.

Renal transplantation (RT) is the best option for patients with end-stage renal disease, but the half-life is limited to a decade due to progressive deterioration of renal function and transplant failure from chronic allograft nephropathy (CAN), which is the leading cause of transplant loss. Extensive research has been done to understand the pathogenesis, the biological pathways of fibrogenesis, and potential therapeutic targets for the prevention and treatment of CAN. Despite the advancements in the immunosuppressive agents and patient care, CAN continues to remain an unresolved problem in renal transplantation. The aim of this paper is to undertake a comprehensive review of the literature on the pathogenesis, biological pathways of RT fibrogenesis, and potential therapeutic targets for the prevention and therapy of CAN.

\section{Introduction}

Renal transplantation (RT) is the best form of treatment for end-stage renal disease (ESRD), because this improves the quality of life and patient survival and is cost-effective [1]. Chronic allograft nephropathy (CAN) is the leading cause of late RT loss; hence, attention has been focussed on understanding the pathogenesis of RT fibrogenesis and interventional strategies to prevent and treat CAN [2].

CAN is characterised by a relatively slow but variable rate of decline in renal function after first 3 months of $\mathrm{RT}$, often in combination with proteinuria and hypertension [3]. CAN should be differentiated from other causes of transplant dysfunction such as rejection (acute, subclinical, and chronic), calcineurin inhibitor (CNI) nephrotoxicity, glomerulonephritis (recurrent and de novo), nephrosclerosis (secondary to old donor age, recipient hypertension, hyperlipidaemia, and smoking), and others (ureteric obstruction, BK virus nephropathy, and transplant renal artery stenosis) $[4,5]$.

Schweitzer et al. from Minnesota in 1991 reported, in a cohort of 2396 patients over a period of 20 years (1970-1989), chronic rejection as the leading cause of graft loss following RT amounting to $24 \%$, followed by death with functioning graft (18\%), infection (13\%), and acute rejection (11\%) [6]. More lately, Sijpkens et al. from Netherlands reported that 54 of the 654 (8\%) RTs performed between 1983 and 1997 had histological evidence of CAN and CAN accounted for $37 \%$ of graft loss after first 6 months post-RT [7]. Naesens et al. have reported that the global burden of early chronic histological damage within the first year after transplantation significantly affected the long-term survival of the allografts [8]. Currently, chronic antibody-mediated rejection from both anti-human leucocyte antigen (HLA) antibodies and non-HLA antibodies is being recognised as an important cause of CAN $[9,10]$.

The aim of this review is to consolidate the published evidence on the pathogenesis, biological pathways of RT fibrogenesis, and potential therapeutic targets for the prevention and therapy of CAN.

\section{Literature Search Strategy}

The literature search was carried out in PubMed and relevant websites using the words "renal transplantation," "chronic allograft nephropathy," "chronic rejection," "graft loss," "transplant fibrosis," and "prevention," Relevant references were compiled in the EndNote software (X6.0.1; Bld 6599). 
TABLE 1: Risk factors implicated in CAN.

\begin{tabular}{|c|c|}
\hline Immunological risk factors & Nonimmunological risk factors \\
\hline $\begin{array}{l}\text { Histocompatibility } \\
\text { Acute rejection episodes } \\
\text { Suboptimal } \\
\text { immunosuppression } \\
\text { Subclinical rejections } \\
\text { Anti-donor antibodies } \\
\text { Noncompliance }\end{array}$ & $\begin{array}{l}\text { Ischaemia-reperfusion injury } \\
\text { Brain death } \\
\text { Infection (cytomegalovirus and BK } \\
\text { virus) } \\
\text { CNI toxicity } \\
\text { Donor factors: age, hypertension, } \\
\text { smoking, diabetes, gender, and } \\
\text { reduced renal mass } \\
\text { Recipient factors: race, hypertension, } \\
\text { smoking, diabetes, and } \\
\text { hyperlipidaemia }\end{array}$ \\
\hline
\end{tabular}

\section{Risk Factors Implicated in CAN}

Both antigen-dependent (immunological) and antigenindependent (nonimmunological) factors are implicated in the aetiology of CAN (Table 1). On occasions, it is difficult to pinpoint a single aetiological factor, as more than one factor is usually implicated in the pathogenesis of CAN [11]. Recurrent episodes of acute tubular-interstitial rejection can explain the interstitial fibrosis and tubular atrophy observed in some cases. Cytokines released during episodes of rejection, including interleukin-1, fibroblast growth factor, and platelet derived growth factor, are likely to play a role in promoting the fibroblast and smooth muscle proliferation seen in allograft vessels. In cases with prior documented intimal arteritis, vessel thickening can be explained as a direct result of immunologic vascular injury. Graft atherosclerosis leads to ischaemic glomerulopathy [12].

Once glomerulosclerosis has developed, the remaining glomeruli undergo compensatory hypertrophy, increased glomerular capillary hydraulic pressure, and increased glomerular filtration. These haemodynamic forces damage the glomerular capillary endothelium, cause mesangial expansion, and accentuate the evolution of chronic transplant glomerulopathy [12]. In support of this hypothesis, it has been shown experimentally that if the increase in glomerular filtration rate is prevented by putting animals on a severely protein restricted diet, the rate of progression of glomerular sclerosis in allograft kidneys is retarded [13, 14]. Arteriolosclerosis and interstitial fibrosis in the allograft may also occur as a result of hypertension, recurrent pyelonephritis, and chronic cyclosporine or tacrolimus toxicity. The relative contribution of these various processes to the ultimate loss of any given allograft may be difficult to determine by pathological evaluation alone. The aetiologically noncommittal term "chronic allograft nephropathy" was in fact coined to accommodate this difficulty [15].

\section{Pathology of CAN}

The kidney affected by CAN looks pale and fibrotic with a dense, thickened, adherent capsule. Under light microscopy, characteristic changes are found in the glomerular, tubuleinterstitial, and microvascular compartments (Figure 1).
4.1. Microvascular Changes. The "transplant arteriopathy" characterised by severe intimal proliferation and luminal narrowing associated with sparse infiltration of T-cells and macrophages is seen in all arteries extending from main renal artery to the interlobar arteries. The intima shows concentric fibrous thickening with intact internal elastic lamina. The matrix appears pale in haematoxylin eosin-stained sections and contains acid mucopolysaccharides, collagen, and increased hyaluronic acid. The cells in the intima include $\alpha$-smooth actin-positive myofibroblasts and smooth muscle cells. The media generally shows no abnormality. Arterioles do not show intimal changes. Hyalinosis of arteries is a feature of CNI toxicity, never seen in animal models not on CNI drug treatment [16].

4.2. Glomerular Changes. In CAN, ischaemic glomeruli, atubular glomeruli, and chronic transplant glomerulopathy are the histological findings. Morphometric analysis of CAN shows populations of small (ischaemic) and large (hyperfiltrating) glomeruli. The ischaemic glomeruli are characterised by wrinkling and collapse of glomerular capillary wall associated with extracapillary fibrotic material [17].

Chronic transplant glomerulopathy (CTG) comprises a spectrum of histological abnormalities which include thickening or duplication of glomerular capillary basement membrane (double contour lesion) and mesangial expansion. CTG implies chronic endothelial injury of glomerular capillary loops and is clinically accompanied by substantial or nephrotic range proteinuria, renal function impairment, and reduced RT survival [18].

4.3. Tubulointerstitial Changes. As a result of ischaemia caused by microvascular changes described above, the tubules undergo atrophy, which may also result from tubulitis. The tubular basement membranes (TBM) are thickened and duplicated, but some show pronounced shrinkage and thinning of TBM and thereby dilatation. The interstitium shows fibrosis with variable mononuclear infiltrate with small lymphocytes, plasma cells, and mast cells. The fibrosis can have different patterns, such as dense and focal, diffuse and fine, striped, or subcapsular. The peritubular capillaries (PTC) are depleted leaving behind only traces of original basement membrane as seen on silver- or PAS-stained sections [19].

4.4. Electron Microscopy. Under electron microscopy, the CTG is associated with deposition of flocculent or fibrillary material; mesangial cellular proliferation with matrix expansion; multilamination or multilayering of the capillary basement membrane. Multilamination of capillary basement membrane as high as seven or more layers indicates past or recent endothelial injury with subsequent repair, which was present in $38 \%$ of failed transplants ascribed to CAN (Figure 2) [20].

\section{Theories of Pathogenesis of CAN}

CAN represents the summated effects of tissue injury resulting from several pathogenic insults and the healing response 


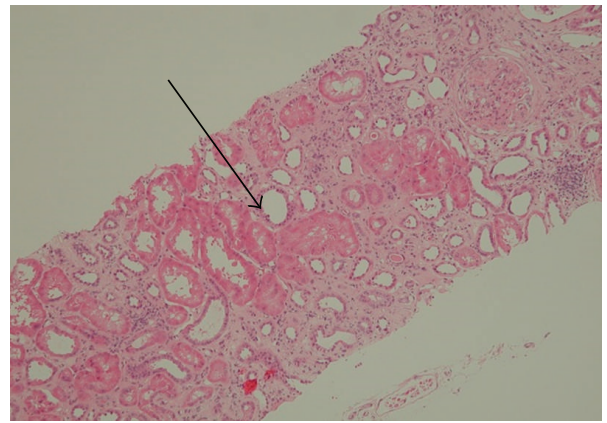

(a)

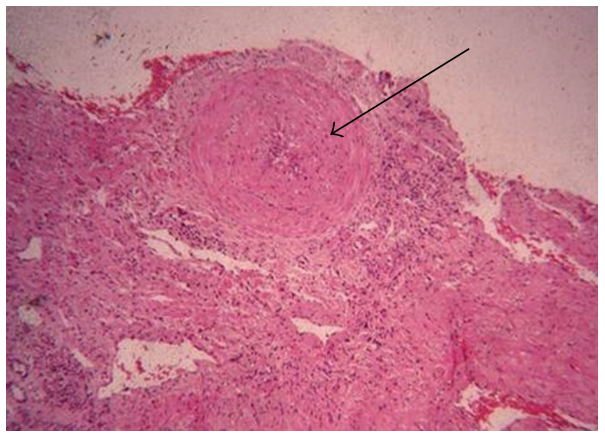

(c)

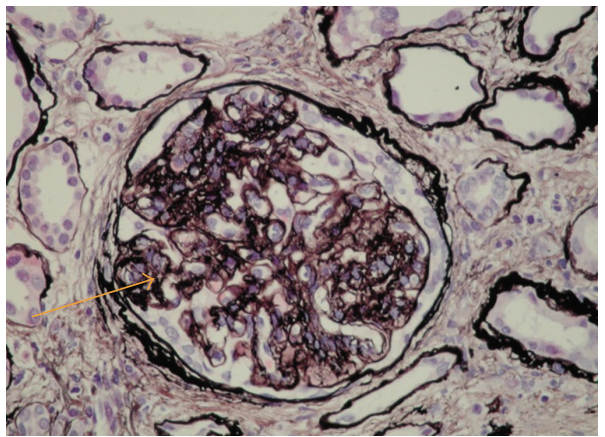

(e)

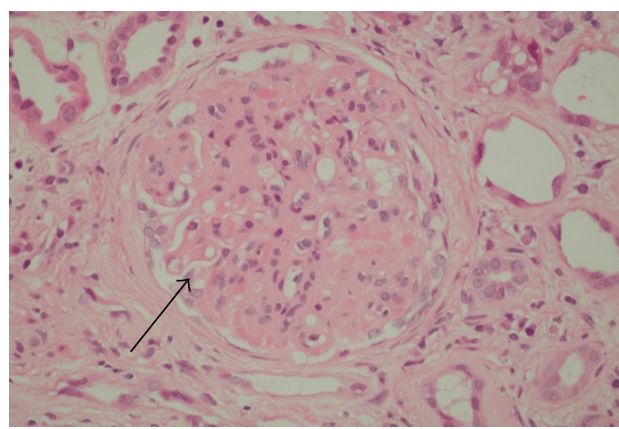

(b)

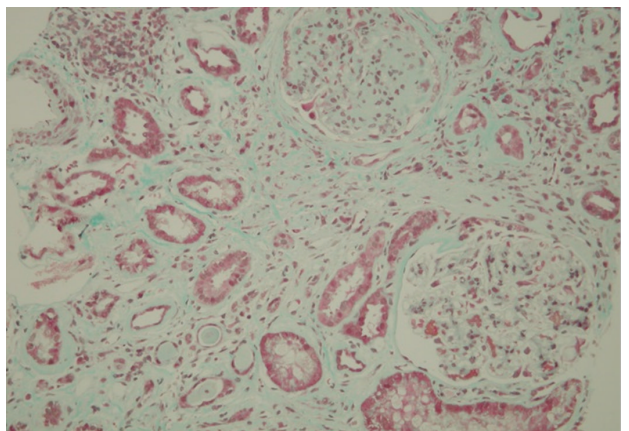

(d)

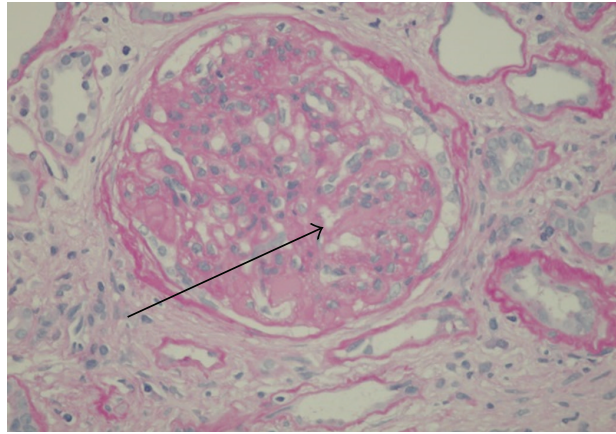

(f)

FIGURE 1: Haematoxylin and eosin (H \& E) stain showing (a) tubular atrophy, interstitial fibrosis $(\rightarrow)$, (b) glomerulosclerosis $(\rightarrow$ ), and $(\mathrm{c})$ concentric obliterative arteriolopathy $(\rightarrow)$; (d) Masson's trichrome stain showing interstitial fibrosis $(\rightarrow)$; (e) silver stain $(\rightarrow)$; and $(f)$ PAS stain showing double contour of glomerular capillary basement membrane $(\rightarrow)$ (magnification $\times 20)$ (source: Northern General Hospital, Sheffield).

of the kidney to injury, in addition to the influence of alloimmunity and immunosuppression. Various hypotheses have been proposed to explain the pathogenesis of CAN, which include (1) chronic rejection, (2) input-stress model, (3) cumulative damage, (4) oxidative stress, (5) cytokine excess, (6) epithelial-mesenchymal transition (EMT) induced fibrosis, (7) replicative senescence, (8) insertion/deletion polymorphism of angiotensin-converting enzyme, and (9) acetylcholine excess [21-30].

\section{Biological Pathways in Allograft Fibrosis}

Majority of extracellular matrix (ECM) in the kidney is composed of collagens I, III, V, VII, and XV and fibronectin. The structural framework is formed by proteoglycans, polysaccharides, and glycoproteins. The tubular basement membrane consists of collagen IV and laminin. Fibrosis or scarring is the overgrowth and sclerosis of the tissues due to the excessive deposition of ECM, which becomes pathological when the functioning architecture is destroyed, leading to functional impairment [31].

The pathway of progression of fibrosis in RT kidney leading to RT loss comprises time-dependent series of pathological insults causing histological changes. There are two broad phases of RT damage observed in sequential biopsy studies, starting with early tubulointerstitial injury [32] followed by later microvascular and glomerular abnormalities and further progressive interstitial fibrosis and tubular atrophy [23]. 


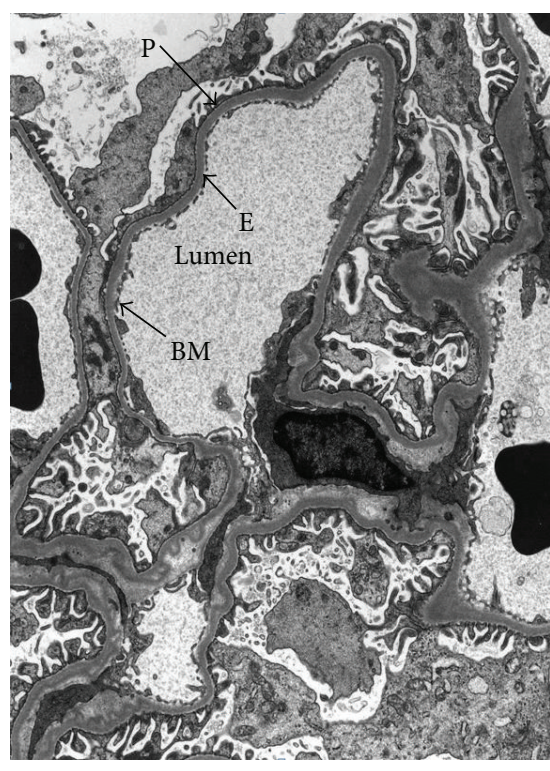

(a)

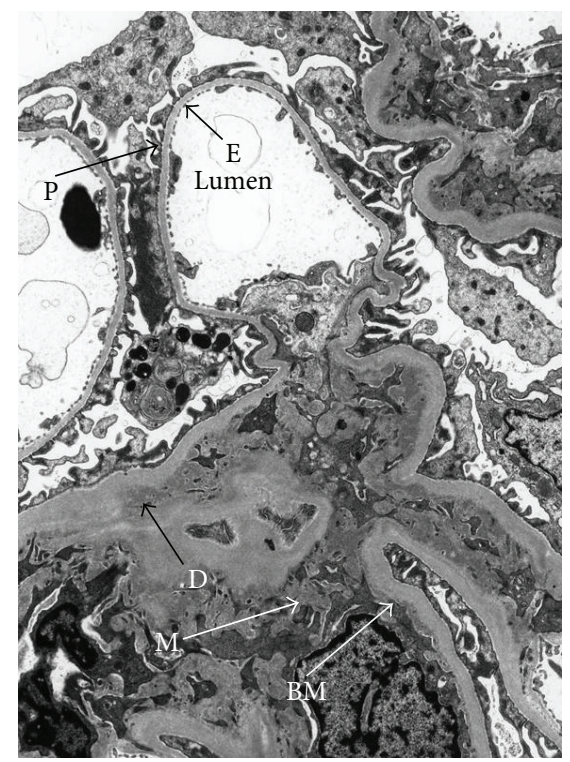

(b)

FIGURE 2: Electron microscopy showing (a) a normal glomerulus (E: endothelial cell; P: podocytes; Lumen: capillary lumen); and (b) transplant glomerulopathy with presence of a well-developed basement membrane (BM) along the entire capillary circumference, mesangial expansion (M), and accumulation of subendothelial deposit (D) (magnification $\times 7000$ ) (source: Northern General Hospital, Sheffield).

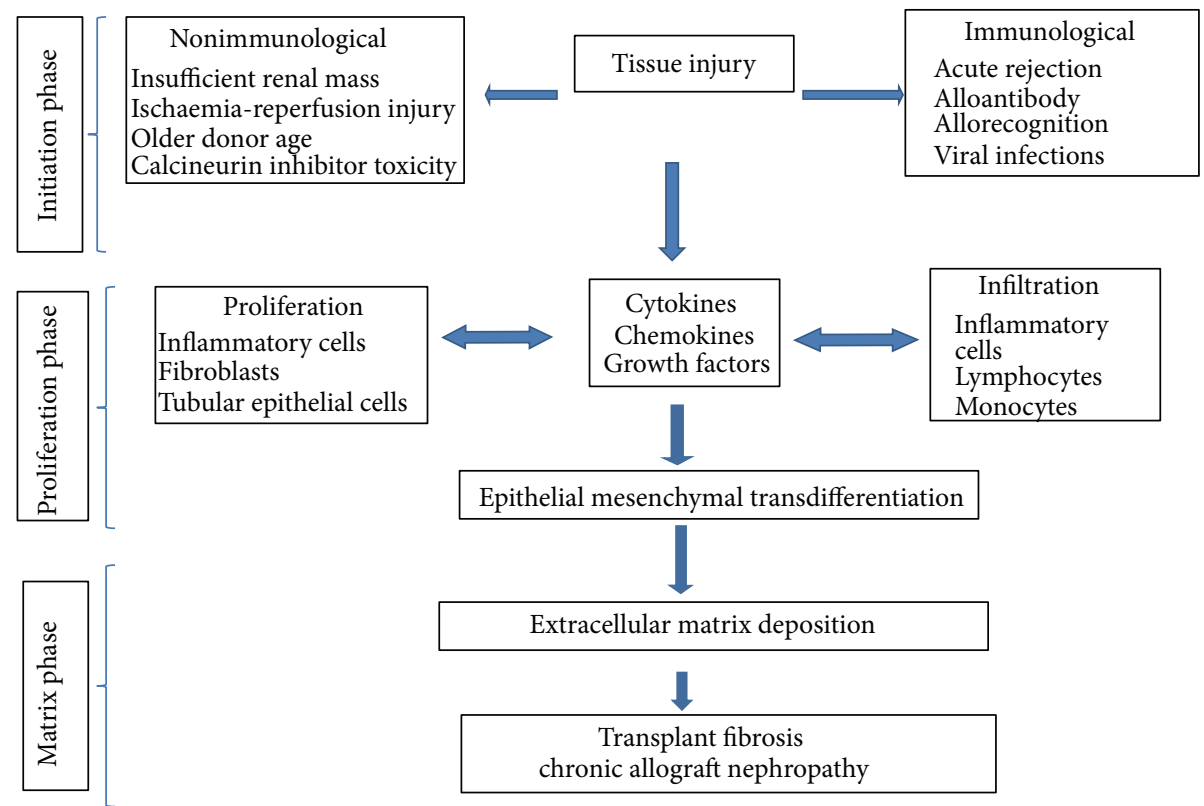

FIGURE 3: Showing pathways of fibrosis in chronic allograft nephropathy.

Figure 3 summarises the events leading fibrosis to CAN and can be arbitrarily divided into three phases, namely, the initiation phase, the fibrogenesis phase, and the matrix accumulation phase. In the initiation phase, tissue injury is caused by antigen-dependent of antigen-independent factors. Regardless of the nature of initiating agent, fibrogenesis phase sets in, which consists of inflammatory and proliferative responses regulated by chemokines, cytokines and growth factors. The cascade of events results in the matrix accumulation phase due to either increased production and/or decreased degradation of matrix, culminating in fibrosis [33].

Injury to the vascular endothelium, glomerular, or tubular epithelium caused by antigen-dependent (immunological) or antigen-independent pathways (toxic, ischaemic, or mechanical) leads to the secretion of proinflammatory mediators (lipid mediators, chemokines, cytokines, adhesion molecules, and growth factors) by all intrinsic renal cells. 
Expression of adhesion molecules and chemokines by the endothelial cells of the glomerular and peritubular capillaries supports leucocyte arrest and transmigration either into the mesangium or the interstitial space. The infiltration and proliferation of leucocytes enhances the local production of cytokines and chemokines. Furthermore, the neutrophils and macrophages generate reactive oxygen species and lipid mediators contributing to local tissue damage and glomerular and tubulointerstitial inflammation, which results in haematuria, leukocyturia, and proteinuria $[34,35]$.

Macrophages themselves secrete ECM components, but they are also major source of growth factors such as fibroblast growth factor (FGF), transforming growth factor- $\beta$ (TGF$\beta$ ), tumour necrosis factor- $\alpha$ (TNF- $\alpha$ ), epithelial growth factor (EGF), and platelet-derived growth factor (PDGF). The TGF- $\beta$ superfamily includes three TGF- $\beta$ isoforms (TGF- $\beta 1$, TGF- $\beta-2$, and TGF- $\beta-3$ ), activins, and bone morphogenetic proteins (BMPs) [36]. Both antigen-dependent and independent injuries lead to the expression of TGF- $\beta$ isoforms, which act by engaging intracellular signalling cascades of canonical SMAD or noncanonical, non-SMAD family of proteins. The SMAD pathways are activated/phosphorylated by TGF- $\beta 1$ receptors such as activins-receptor like kinase (ALK) 5 and ALK1. However, TGF- $\beta$ also activates the noncanonical, SMAD-independent pathways such as Ras/rho and MAPK, NF-kB, or PI3kinase/AKT pathway. Receptoractivated SMAD protein complexes translocate within the nucleus and initiate transcription of target genes [37-39].

TGF- $\beta 1$ is the key modulator of glomerulosclerosis, tubulointerstitial fibrosis, and EMT in the kidney. TGF$\beta 1$ sets off a cascade of profibrotic molecules through the activation of SMAD2/3 [40] and MEK signalling pathways [41], which results in the transcription of genes and activation of molecules involved in matrix deposition and fibrosis. Proinflammatory and profibrotic cytokines stimulate the proliferation of mesangial cells in the glomerulus and of interstitial fibroblasts in the interstitium, which, upon activation, increase the synthesis of extracellular matrix components. Leucocyte infiltration, fibroblast proliferation, and matrix deposition as well as oedema increase the interstitial volume. There is proliferation of resident fibroblasts and of the myofibroblasts derived from tubular epithelial cells by a process of EMT, induced by the macrophage-derived, profibrotic cytokine FGF-2 [42]. In the glomeruli, stimulated mesangial cells secrete the collagen type IV, laminin, and fibronectin that contribute to glomerulosclerosis [43]. Mesangial expansion leads to narrowing, obliteration, or dilatation of glomerular capillaries. This results in damage to podocytes and downstream peritubular capillaries leading to destruction of entire nephrons [44].

The tubulointerstitial compartment shows progressive expansion of ECM through continuous stimulation of fibroblasts. Transdifferentiation of activated tubular epithelial cells leads ECM expansion. Massive increase in interstitial volume from infiltrates and expansion of ECM leads to an increase in the distance between the peritubular capillaries and the tubules, thereby impairing oxygen diffusion as well as tubular reabsorption and excretory function [45]. The tubulointerstitial ischaemia is considered to be an important factor for tubular cell apoptosis, necrosis, and tubular atrophy [46]. Finally, extensive loss of transplant renal parenchyma leads to transplant failure. At a late stage of CAN, although the leucocytic infiltration resolves, renal fibroblasts maintain the synthesis of ECM due to sustained hypoxia and autocrine stimulation [47]. Myofibroblasts contribute to the contraction of the fibrous tissue with scarring leading to a shrunken transplant kidney at the terminal stage.

\section{Potential Targets for Prevention and Therapy of CAN}

The modulation of fibrosis is central in RT. As CAN is the end result of injury caused by acute rejection, infection, ischaemia reperfusion injury, alloantibody-mediated rejection, and drug toxicity, each factor needs to be prevented and treated appropriately. Shortening of cold ischaemia time, HLA-matching and reduced sensitisation, avoidance of CNI-toxicity, cytomegalovirus prophylaxis, and treatment of subclinical rejection detected through protocol biopsies are paramount [48]. Early detection of changes of CAN by microarray mRNA assays, which detect alteration in the transcriptomes at a very early stage of interstitial fibrosis, even before infiltration by inflammatory cells, has opened up a new avenue for interventions at this stage [35, 49]. At the molecular level, targeting the blockade of synthesis or action of enzymes, cytokines, chemokines, and growth factors at various stages of renal fibrogenesis is being investigated, both in experimental and clinical settings, which are discussed below.

7.1. Chemokine Blockade. Blockade of chemokines (BX471: CCR1 antagonist; and met-RANTES: RANTES antagonist) is proven to be effective in preventing RT fibrosis in rat transplant models. No parallel study has been carried out in human RTs [50,51]. Chemokines are a family of small size $(8-10 \mathrm{kDa})$ chemotactic cytokines, which, in transplantation, induce recruitment and activation of $\mathrm{T}$ cells and monocytes or macrophages. So far more than 50 chemokines and 20 chemokine receptors have been identified. Members of chemokines family are divided into four groups (C, CC, $\mathrm{CXC}$, and $\mathrm{CX}_{3} \mathrm{C}$ ) based upon the position of their first two cysteine residues. They are further classified as inflammatory or haemostatic.

In Fisher-to-Lewis rat allografts, BX-471, chemokine receptor type 1 (CCR1) antagonist, prevented the infiltration of T cells and macrophages, decreased cell proliferation (ED1, $\mathrm{CD} 8$, and Ki67), and reduced expression of acute phase reactive proinflammatory genes (HO-1, osteopontin) and molecules associated with fibrosis (PAI-1, TGF- $\beta$, and biglycan). There was a significantly lower number of SMA-positive interstitial myofibroblasts and reduction in the deposition of collagen [51].

Similarly, Met-RANTES, a chemokines receptor antagonist (CCR5), in Fisher-to-Lewis allografts, blocked the effects of RANTES (regulated on activation, normal Tcell expressed) reducing the infiltration of lymphocytes and macrophages in allografts, accompanied by decreased mRNA 
expression of interleukin (IL)-2, IL-1 beta, tumour necrosis factor-alpha (TNF-alpha), and RANTES and thereby reduced glomerulosclerosis, tubulointerstitial fibrosis, and proteinuria [50].

7.2. Blockade of Oxidative Stress. In human RT, intraoperativeadministration of recombinant human superoxide dismutase decreased the incidence of acute and chronic rejection [52], whereas treatment pre- and postreperfusion made no difference in allograft function 48 hours after transplant [53]. Further clinical trials are needed to determine the type, dose, and timing of antioxidant intervention.

7.3. Renin-Angiotensin System Blockade. Angiotensin II activates TGF- $\beta 1$, apoptosis, oxidative stress, and atherogenesis in the cardiovascular system and the kidney [54-56]. Reninangiotensin system (RAS) blockade has antifibrotic and antiproteinuric properties in experimental and clinical studies of kidney diseases. Angiotensin II, acting via aldosterone, increases plasminogen activator inhibitor-1 (PAI-1) and limits plasmin production from plasminogen, resulting matrix overproduction. Angiotensin-converting enzyme inhibitors (ACE-I) and angiotensin (Ang) II receptor blockade lead to reduced intragraft expression of TGF- $\beta$ and reduced proteinuria. Therefore, this has now become the first line therapy in patients with CKD and hypertension or proteinuria [57].

A large retrospective study of over 2000 RT recipients showed that 10 -year patient and graft survival was significantly improved in individuals treated with ACE-I or Ang II receptor blockers [58]. A meta-analysis of 21 randomised controlled trials including 1549 patients showed that RAS blockade was associated with significant drop in haematocrit $(-3.5 \%)$, GFR $(-5.8 \%)$, and proteinuria $(-0.47 \mathrm{~g} / \mathrm{d})$ during a 2-year time period, but there are insufficient data to determine the effect on patient or graft survival [59].

In comparison with patients with native kidney disease, there is little information from prospective randomised controlled trials examining the effects of RAS blockade on long-term outcomes in RT. The ongoing Canadian ACE-I trial (ISR-78129473) and American Angiotensin II Blockade for the prevention of cortical interstitial expansion and graft loss in RT recipients (NCT00067990) studies will provide clinically meaningful evidence on the effect of RAS blockade on patient and graft survival in RT recipients $[59,60]$.

7.4. Inhibition of TGF- $\beta 1$. TGF- $\beta 1$ is upregulated in animal and human allografts undergoing chronic rejection and in chronic cyclosporine-induced tubulointerstitial fibrosis [61, $62]$. On the other hand, TGF- $\beta 1$ exerts immunosuppressive effects in the RT and helps the generation of T-regulatory cells thereby inducing certain degree of graft tolerance, which is beneficial to the graft. Therefore, caution needs to be exercised in blockade of TGF- $\beta 1$. For example, TGF$\beta 1$ knockout mice die at an early stage from uncontrolled multifocal inflammatory disease and evidence suggests that overexpression of TGF- $\beta 1$ in early acute rejection may prevent chronic rejection and improved outcomes $[63,64]$; hence, TGF- $\beta 1$ may be a less than optimal target in transplant settings. Alternatively, downstream targets may be more useful approach. To date, no clinical trial has been undertaken on the use of TGF- $\beta 1$ in human RT. Agents, used to inhibit TGF- $\beta 1$, are described below.

7.4.1. Pirfenidone. Pirfenidone (PFD) (5-methyl-a-phenyl-2$(1 \mathrm{H})$-pyridone) is an orally active synthetic agent that inhibits expression of TGF- $\beta 1$, epidermal growth factor, PDGF, and fibroblast proliferation [65]. In a rat model of cyclosporine nephrotoxicity, PFD reduced TGF- $\beta$ mRNA protein expression and fibrosis by $50 \%$ and reduced proapoptotic gene expression $[65,66]$. Administration of PFD in focal segmental glomerulosclerosis led to $25 \%$ improvement in the rate of decline of kidney function [67]. PFD has not been tested in human clinical transplantation yet.

7.4.2. Relaxin. Relaxin is a peptide hormone, a member of insulin growth factor (IGF) family, and a naturally occurring inhibitor of collagen deposition during normal development, aging, and pregnancy. In cultured human renal fibroblasts, exposure to relaxin inhibited TGF- $\beta$-induced type I collagen and fibronectin synthesis and signalling via SMAD2 and also stimulated matrix metalloproteinase (MMP)-2 and 9 secretion [68]. Furthermore, in a relaxin gene-knockout mouse, the progressive renal fibrosis and deteriorating renal function were reversed with recombinant relaxin [69]. In a bromoethylamine-induced model of renal fibrosis in the rat, relaxin administration was associated with a significant decrease in interstitial fibrosis at the corticomedullary junction, accompanied by a decrease in the number of ED-1 positive cells (an index of macrophage infiltration) and in the intensity of immunohistochemical staining for transforming growth factor-beta [70]. However, there have been no preclinical studies in transplantation.

7.4.3. Decorin. Decorin is a small leucine rich proteoglycan that forms complexes with TGF- $\beta$ leading to inhibition or sequestration within the ECM. In experimental models of obstructive uropathy, treatment with decorin reduced proteinuria, collagen deposition, and expression of TGF- $\beta$ within the kidney [71, 72].

7.4.4. Endothelin-1 Inhibition. Endothelin-1 (ET-1) is a vasoactive peptide with potent vasoconstrictive properties, which is produced in tubular epithelium, macrophages, and fibroblasts. ET-1 also promotes fibrogenesis by upregulating TGF$\beta$, directly stimulates collagen synthesis, and limits collagen degradation [73]. The use of nonselective ET-1 receptor blockade in an ischaemic injury rat model limited the fall in GFR [74]. Bosentan, a nonselective ET antagonist, has been used in a rat tracheal allograft model where it ameliorated bronchiolitis obliterans, but the experience of ET-1 receptor blockade in clinical transplantation is limited [75].

7.4.5. Bone Morphogenetic Protein-7 (BMP-7). BMP-7 is a member of the TGF $\beta-1$ family, which signals through the ALK3 and ALK6 type I receptors to phosphorylate SMAD1, SMAD5, and SMAD8, whereas TGF $\beta 1$ signals through the 
ALK5 type 1 receptor to phosphorylate SMAD2 and SMAD3 [76]. BMP-7 can counterbalance the profibrotic effects of TGF $\beta-1$ by the activation of regulatory SMAD1, SMAD5, and SMAD8. It was observed that renal allografts with tubulointerstitial fibrosis and EMT were associated with upregulation of intraepithelial phospho-SMAD2/3 and concomitant downregulation of phospho-SMAD1/5/8, whereas BMP-7 increased phosphor-SMAD1/5/8 in renal cortical epithelial cells in vitro [37].

7.4.6. Connective Tissue Growth Factor (CTGF). CTGF is heparin binding cysteine-rich protein that gets activated through SMAD and MEK pathways; thereby it activates TGF$\beta 1$ and inhibits the antifibrotic effects of BMP-7. The net effect leads to cellular proliferation, collagen synthesis, chemotaxis, and EMT $[77,78]$.

CTGF mRNA and protein levels were increased in a mouse model of kidney transplantation. In vitro studies showed CTGF to induce EMT in tubular epithelial cells. Furthermore, urinary CTGF levels were increased in RT recipients with chronic allograft fibrosis [79]. In Fisher-toLewis RT model, CTGF silencing with siRNA decreased allograft fibrosis [80]. No studies on the role of CTGF in clinical RT have been performed.

7.4.7. SMAD and Rho GTPases Inhibition. TGF- $\beta 1$ activates SMAD $2 / 3$ by phosphorylation through the ALK type I receptor. It can also activate Ras/rho and the downstream MEK pathway through noncanonical SMAD-independent pathway [81]. Targeting these downstream molecules in the TGF- $\beta 1$ signalling pathway is an alternative antifibrotic strategy.

In experimental models, inhibition of SMAD3 and rho prevented fibrogenesis. In unilateral ureteric obstruction (UUO) model of SMAD3 knockout mice, minimal renal fibrosis was observed [82]. In the UUO mice model, a rhoassociated coiled-coli forming protein kinase inhibitor (Y27632) prevented the transcription of fibrosis genes including TGF- $\beta 1, \alpha$-smooth muscle actin ( $\alpha$-SMA), and $\alpha 1$-collagen and matrix deposition [83]. Fasudil, a specific rho kinase inhibitor, attenuated myocardial fibrosis and interstitial fibrosis in experimental models of diabetic and obstructive uropathy [84]. However, no preclinical or clinical studies have examined the role of such intervention in renal allografts.

7.4.8. Vascular Endothelial Growth Factor (VEGF). VEGF is an antigenic factor expressed in glomerular podocytes and distal tubules in response to stimuli such as hypoxia, TGF$\beta 1$, epidermal growth factor, and PDGF. VEGF is an inducer of proliferation (extracellular signal-regulated kinases), permeability (endothelial fenestration), invasion (matrix metalloproteinases), and survival (activation of Akt/P13K, caspase inhibition) [85].

One study has examined the influence of VEGF on renal function and development of interstitial fibrosis in renal allografts in 92 patients with acute rejection, CAN, and acute cyclosporine toxicity. Increased VEGF expression was correlated with increased expression of TNF- $\alpha$ levels and macrophage infiltration, associated with increased risk of early interstitial fibrosis and poor graft outcome in long term [86].

7.4.9. Hepatocyte Growth Factor (HGF). Hepatocyte growth factor (HGF) was originally identified and cloned as a potent mutagen for mature hepatocytes. It is now clear that HGF acts on various types of cells through its MET receptor tissue kinase and elicits pleiotropic effects involved in embryogenesis and tissue repair [87].

HGF prevents the initiation and progression of renal fibrosis by inhibiting TGF- $\beta 1$ expression, myofibroblasts activation, and EMT. It can block the nuclear translocation of SMAD-2/3 and upregulate the expression of SMAD transcriptional compressors, Sloan Kettering Institute (SKI)related novel protein $\mathrm{N}(\mathrm{SnoN})$, and TG-interacting factors (TGIF) [88].

In a rat model of CAN, treatment with human recombinant HGF prevented renal allograft inflammation (decreased TNF- $\alpha$, MCP-1, and iNOS mRNA levels) and fibrosis (decreased TGF- $\beta 1$ mRNA and matrix accumulation) [89]. Similar results were observed following human HGF gene therapy immediately before and after RT in rats [90]. However, HGF therapy in RT recipients may be associated with the potential risk of cancer, given that the HGF receptor is a tyrosine kinase receptor involved in progression of carcinomas and metastasis [91].

\subsection{Inhibition of Matrix Deposition}

7.5.1. Prolyl-4-hydroxylase Inhibitors. In collagen synthesis, prolyl-4-hydroxylase is essential in posttranslational modification of the alpha chains of procollagen. Inhibition of this enzyme prevents hydroxylation of proline of the procollagen chain, subsequently causing intracellular degradation of the procollagen and reduction in the collagen deposition in the interstitium [92].

Phenanthrolinone, a competitive inhibitor of prolyl-4hydroxylase, was studied in a murine model of CAN, which demonstrated reduction in inflammation and graft fibrosis along with improvement in graft function. The drug was used once wounds had healed. Clinical application of this agent needs to be established [93].

7.5.2. $M M P-2, M M P-3$, and MMP-9 Inhibitor (Bay 12-9566). In rat renal allografts, fibrosis is associated with increased expression of MMP-2 and MMP-9 and decreased tissue inhibitor of matrix metalloproteinases (TIMP)-3 [94]. BAY 12-9566, an inhibitor of MMP-2, MMP-3, and MMP-9 given early in the posttransplant period, improved proteinuria and histology. However, institution at late time-point appeared to aggravate disease [95].

7.5.3. Retinoids. Retinoids have been recognised for their anti-inflammatory capacity and their specific receptors are expressed within the kidney as well as T- and B-cells and macrophages [96]. Treatment with isotretinoin (13-cisRA) in a chronic rat allograft model reduced interstitial fibrosis 
and inflammatory cell infiltration and is considered as an important therapeutic approach when chronic rejection and immune response are implicated in the allograft injury [97].

7.6. Platelet-Derived Growth Factor (PDGF) Inhibitors. PDGF is a family composed of PDGF-A, PDGF-B, PDGF-C, and PDGF-D, which are potent growth factors for myofibroblasts, and exerts their cellular effects by binding to tyrosine kinase receptors- $\alpha$ and $-\beta$. PDGFs play pivotal roles in wound healing, regulation of interstitial fluid pressure, malignancies, atherosclerosis, and fibrotic diseases [98]. The increased expression of PDGF has been observed in both animal (mesangioproliferative and rat transplant models) and human (proliferative GN and diabetic nephropathy, transplant glomerulopathy) renal diseases [99-102]. PDGF was present at glomeruli and proximal tubular cells and in areas of peritubular, interstitial, and periglomerular fibrosis.

In the Dark Agouti to Wistar-Furth rat model of CAN, imatinib (STI571), a selective PDGF receptor tyrosine kinase inhibitor, prevented the development of CAN and preserved renal function [103]. In the same model, similar results were observed with FK778, a synthetic analogue of an active metabolite of leflunomide, which inhibited de novo biosynthesis of pyrimidine and prevented activation of both T- and B-lymphocytes and expression of TGF- $\beta$ ligand and receptor [104].

7.7. Nuclear Factor Kappa-B (NF- $\kappa B)$ Signalling Inhibitors. $\mathrm{NF}-\kappa \mathrm{B}$ comprises a family of transcription factors. NF- $\kappa \mathrm{B}$ pathway is activated by TNF- $\alpha$, IL-1, and LPS or stressmediated cascades. Upon translocation of NF- $\kappa \mathrm{B}$ into the nucleus from cytoplasm, it binds to the DNA and regulates production of various cytokines, chemokines, stress response proteins, and antiapoptotic proteins.

Activation of $\mathrm{NF}-\kappa \mathrm{B}$ is observed in both animal (rat model of glomerulonephritis) and human (diabetic nephropathy) renal diseases $[105,106]$. The $\mathrm{NF}-\kappa \mathrm{B}$ positive nuclei were seen in the mesangial cells, endothelial cells, podocytes, tubular cells, and mononuclear infiltrates in the interstitium. In both studies, phosphorylation of p38MAP kinase was observed.

Inhibition of NF- $\kappa \mathrm{B}$ using pyrrolidone dithiocarbamate (PDTC), steroids (prednisolone and dexamethasone), gliotoxin, parthenolide, and proteasome inhibitor N-benzyloxycarbonyl-Ile-Glu (o-t-Bu)-Ala-Leucinal has been examined in rat models. Significant reduction in inflammation, development of fibrosis by reducing MCP-1 gene, and profibrotic gene expression were observed [107-109].

Activation of $\mathrm{NF}-\kappa \mathrm{B}$ was inhibited on human proximal tubular cells when treated with mycophenolic acid [110]. Bortezomib, a proteasome inhibitor, was shown to reduce antibody production and reduce vasculopathy in rat cardiac transplantation models [111]. Case reports on the use of Bortezomib for antibody-mediated rejection are available in human renal transplantation, but its clinical application is still in experimental stage [112].

\section{Biomarkers of CAN}

Several biomarkers of CAN have been examined for early detection and prediction of CAN, which still remain in investigative stage. Chemokine (C-C motif) ligand 2 (CCL2), also known as monocyte chemotactic protein-1 (MCP-1), recruits monocytes, memory $\mathrm{T}$ cells, and dendritic cells to the sites of tissue injury, infections, and inflammation. Urinary CCL2 was measured and protocol biopsies performed prospectively in 111 RT recipients at 0,6 , and 24 months, which demonstrated urinary CCL 2 at 6 months as an independent risk factor for subsequent development of IFTA at 24 months, both in univariate and multivariate analyses [113].

Proteomic analysis of blood samples using mass spectrometry has identified several unique signatures of transcript and protein biomarkers with high predictive accuracies for mild and moderate/severe CAN, which can be used for proteogenomic classification of CAN based on peripheral blood profiling, although the validity remains to be proven $[114,115]$.

In 2003, Scherer et al., in their genomics study using microarray technology, detected upregulation of several genes, which could predict the development of CAN. Those genes were APRIL (acidic protein rich in leucines), OBCML (opiate-binding protein-cell adhesion molecule-like), the tumour suppressor gene NPRL2, cytokeratin 15, homeobox gene $\mathrm{B}$, prolactin receptor, and guanine nucleotide-binding protein g7 [116]. The same group also demonstrated early changes in several transcriptomes post-RT, which could predict development of CAN and identify patients at risk [117]. More recently, Einecke et al. examined RT biopsy specimens that showed genes associated with graft failure were related to tissue injury, epithelial dedifferentiation, matrix remodelling, and TGF- $\beta$. In multivariate analysis, molecular risk score, peritubular capillary basement membrane multilayering, arteriolar hyalinosis, and proteinuria were independent predictors of graft loss [118].

Oetting et al. from Minnesota have investigated the effect of telomere length (TL) on the allograft survival and CAN by measuring TL in DNA isolated from peripheral blood in 1805 recipients and 1038 living kidney donors using the multiplexed monochrome quantitative polymerase chain reaction assay. They concluded that the CAN was not associated with shorter TL, although older donor chronological age was associated with increased risk of CAN [119]. Molecular profiling is a newer advancement in identifying molecular signatures related to CAN. Maluf et al. have identified calcineurin inhibitor toxicity at the molecular level as a nonimmunological factor involved in the progression to CAD [120].

\section{Conclusions}

CAN, once established, is irreversible $[3,23]$. Delaying the progression of renal fibrosis and preservation of allograft function should be the goal, which is being achieved through substitution with less nephrotoxic immunosuppressive agents 
and modification of risk factors, such as adequate control of hypertension, diabetes, hyperlipidaemia, proteinuria (angiotensin blockade), and infections (CMV, BKV, and urine tract infections). CNI minimisation and steroid-sparing regimens were shown to reduce the progression of CAN [121, 122]. Substitution of CNIs with sirolimus and mycophenolate mofetil leads to improvement and preservation of renal function in CAN cases $[123,124]$. Early diagnosis of CAN through protocol biopsies and institution of appropriate immunosuppressive regimens and treatment of subclinical rejection is essential to prevent late diagnosis of CAN [125].

Several interventional strategies have been examined to block the intracellular and extracellular cascades of events at molecular levels in both clinical and experimental settings to prevent CAN, but limited success has been achieved $[33,49]$. Preventive and treatment strategies targeting TGF$\beta 1$ signalling pathway are reasonable antifibrotic options in $\mathrm{RT}$, but TGF- $\beta$ expression in RT is being considered to be beneficial because of its effect in gaining tolerance [33]. More specifically, PFD and therapies targeting BMP-7, HGF, and CTGF, although having shown promising results, still are in the experimental phase [76]. Exploration of alternative pathways and downstream molecules is critical for developing new strategies to ameliorate graft fibrosis and atrophy. Clinical trials are needed to examine their long-term effects in RT. Modulation of the risk factors, both immunological and nonimmunological, have been successful in slowing down the progression of CAN to some extent, but not successful in prevention or reversal of the ultimate changes of CAN [126128].

\section{Conflict of Interests}

The authors declare that there is no conflict of interests regarding the publication of this paper.

\section{References}

[1] A. Shrestha, A. Shrestha, C. Basarab-Horwath, W. McKane, B. Shrestha, and A. Raftery, "Quality of life following live donor renal transplantation: a single centre experience," Annals of Transplantation, vol. 15, no. 2, pp. 5-10, 2010.

[2] U. Heemann and J. Lutz, "Pathophysiology and treatment options of chronic renal allograft damage," Nephrology, Dialysis, Transplantation, vol. 28, no. 10, pp. 2438-2446, 2013.

[3] L. C. Paul, "Chronic allograft nephropathy: an update," Kidney International, vol. 56, no. 3, pp. 783-793, 1999.

[4] L. D. Cornell and R. B. Colvin, "Chronic allograft nephropathy," Current Opinion in Nephrology and Hypertension, vol. 14, no. 3, pp. 229-234, 2005.

[5] M. Haas, "Chronic allograft nephropathy or interstitial fibrosis and tubular atrophy: what is in a name?" Current Opinion in Nephrology and Hypertension, vol. 23, no. 3, pp. 245-250, 2014.

[6] E. J. Schweitzer, A. J. Matas, K. J. Gillingham et al., "Causes of renal allograft loss: progress in the 1980s, challenges for the 1990s," Annals of Surgery, vol. 214, no. 6, pp. 679-688, 1991.

[7] Y. W. J. Sijpkens, I. I. N. Doxiadis, F. J. van Kemenade et al., "Chronic rejection with or without transplant vasculopathy," Clinical Transplantation, vol. 17, no. 3, pp. 163-170, 2003.
[8] M. Naesens, D. R. J. Kuypers, K. De Vusser et al., "Chronic histological damage in early indication biopsies is an independent risk factor for late renal allograft failure," American Journal of Transplantation, vol. 13, no. 1, pp. 86-99, 2013.

[9] T. K. Sigdel, L. Li, T. Q. Tran et al., "Non-HLA antibodies to immunogenic epitopes predict the evolution of chronic renal allograft injury," Journal of the American Society of Nephrology, vol. 23, no. 4, pp. 750-763, 2012.

[10] J. Pascual, M. J. Pérez-Sáez, M. Mir, and M. Crespo, “Chronic renal allograft injury: early detection, accurate diagnosis and management," Transplantation Reviews, vol. 26, no. 4, pp. 280290, 2012.

[11] L. C. Paul, "Pathogenesis of chronic allograft nephropathy," Current Opinion in Nephrology and Hypertension, vol. 7, no. 6, pp. 635-637, 1998.

[12] R. K. Maryniak, M. R. First, and M. A. Weiss, "Transplant glomerulopathy: evolution of morphologically distinct changes," Kidney International, vol. 27, no. 5, pp. 799-806, 1985.

[13] B. M. Brenner, E. V. Lawler, and H. S. Mackenzie, "The hyperfiltration theory: a paradigm shift in nephrology," Kidney International, vol. 49, no. 6, pp. 1774-1777, 1996.

[14] B. M. Brenner, T. W. Meyer, and T. H. Hostetter, "Dietary protein intake and the progressive nature of kidney disease: the role of hemodynamically mediated glomerular injury in the pathogenesis of progressive glomerular sclerosis in aging, renal ablation, and intrinsic renal disease," The New England Journal of Medicine, vol. 307, no. 11, pp. 652-659, 1982.

[15] M. R. Weir and R. K. Wali, "Minimizing the risk of chronic allograft nephropathy," Transplantation, vol. 87, no. 8, pp. S14S18, 2009.

[16] S. M. Lal, A. M. Luger, L. K. Saha, and G. Ross Jr., "De novo membranous glomerulopathy in renal allografts with unusual histology," International Journal of Artificial Organs, vol. 18, no. 2, pp. 78-80, 1995.

[17] D. Y. Tsay, J. D. Lian, K. H. Shu et al., "Glomerular diseases in human renal allograft," Journal of the Formosan Medical Association, vol. 90, no. 11, pp. 1038-1043, 1991.

[18] F. Ortiz, T. Paavonen, T. Törnroth et al., "Predictors of renal allograft histologic damage progression," Journal of the American Society of Nephrology, vol. 16, no. 3, pp. 817-824, 2005.

[19] P. Boor, T. Ostendorf, and J. Floege, "Renal fibrosis: novel insights into mechanisms and therapeutic targets," Nature Reviews Nephrology, vol. 6, no. 11, pp. 643-656, 2010.

[20] B. Ivanyi, E. Kemeny, E. Szederkenyi, F. Marofka, and P. Szenohradszky, "The value of electron microscopy in the diagnosis of chronic renal allograft rejection," Modern Pathology, vol. 14, no. 12, pp. 1200-1208, 2001.

[21] Z. A. Massy, C. Guijarro, M. R. Wiederkehr, J. Z. Ma, and B. L. Kasiske, "Chronic renal allograft rejection: immunologic and nonimmunologic risk factors," Kidney International, vol. 49, no. 2, pp. 518-524, 1996.

[22] P. F. Halloran, A. Melk, and C. Barth, "Rethinking chronic allograft nephropathy: the concept of accelerated senescence," Journal of the American Society of Nephrology, vol. 10, no. 1, pp. 167-181, 1999.

[23] B. J. Nankivell, R. J. Borrows, C. L.-S. Fung, P. J. O’Connell, R. D. M. Allen, and J. R. Chapman, "The natural history of chronic allograft nephropathy," The New England Journal of Medicine, vol. 349, no. 24, pp. 2326-2333, 2003.

[24] A. Djamali, "Oxidative stress as a common pathway to chronic tubulointerstitial injury in kidney allografts," American Journal of Physiology, vol. 293, no. 2, pp. F445-F455, 2007. 
[25] A. Benigni, I. Bruzzi, M. Mister et al., "Nature and mediators of renal lesions in kidney transplant patients given cyclosporine for more than one year," Kidney International, vol. 55, no. 2, pp. 674-685, 1999.

[26] A. Hertig, J. Verine, B. Mougenot et al., "Risk factors for early epithelial to mesenchymal transition in renal grafts," American Journal of Transplantation, vol. 6, no. 12, pp. 2937-2946, 2006.

[27] A. Djamali, S. Reese, J. Yracheta, T. Oberley, D. Hullett, and B. Becker, "Epithelial-to-mesenchymal transition and oxidative stress in chronic allograft nephropathy," American Journal of Transplantation, vol. 5, no. 3, pp. 500-509, 2005.

[28] A. Melk, "Senescence of renal cells: molecular basis and clinical implications," Nephrology Dialysis Transplantation, vol. 18, no. 12, pp. 2474-2478, 2003.

[29] M. Siekierka-Harreis, N. Kuhr, R. Willers et al., "Impact of genetic polymorphisms of the renin-angiotensin system and of non-genetic factors on kidney transplant function-a singlecenter experience," Clinical Transplantation, vol. 23, no. 5, pp. 606-615, 2009.

[30] J. Wilczynska, U. Pfeil, A. Zakrzewicz et al., "Acetylcholine and chronic vasculopathy in rat renal allografts," Transplantation, vol. 91, no. 3, pp. 263-270, 2011.

[31] H. Abo-Zenah, S. Katsoudas, D. De Takats et al., "Early progressive interstitial fibrosis in human renal allografts," Clinical Nephrology, vol. 57, no. 1, pp. 9-18, 2002.

[32] D. R. J. Kuypers, J. R. Chapman, P. J. O’Connell, R. D. M. Allen, and B. J. Nankivell, "Predictors of renal transplant histology at three months," Transplantation, vol. 67, no. 9, pp. 1222-1230, 1999.

[33] R. B. Mannon, "Therapeutic targets in the treatment of allograft fibrosis," American Journal of Transplantation, vol. 6, no. 5, pp. 867-875, 2006.

[34] H. Amer and M. D. Griffin, "Modulating kidney transplant interstitial fibrosis and tubular atrophy: is the RAAS an important target?" Kidney International, vol. 85, no. 2, pp. 240-243, 2014.

[35] R. L. Heilman, Y. Devarapalli, H. A. Chakkera et al., "Impact of subclinical inflammation on the development of interstitial fibrosis and tubular atrophy in kidney transplant recipients," American Journal of Transplantation, vol. 10, no. 3, pp. 563-570, 2010.

[36] E. P. Böttinger, “TGF- $\beta$ in renal injury and disease," Seminars in Nephrology, vol. 27, no. 3, pp. 309-320, 2007.

[37] J. R. Tyler, H. Robertson, T. A. Booth, A. D. Burt, and J. A. Kirby, "Chronic allograft nephropathy: intraepithelial signals generated by transforming growth factor- $\beta$ and bone morphogenetic protein-7," American Journal of Transplantation, vol. 6, no. 6, pp. 1367-1376, 2006.

[38] J. Zavadil and E. P. Böttinger, "TGF- $\beta$ and epithelial-tomesenchymal transitions," Oncogene, vol. 24 , no. 37 , pp. $5764-$ 5774, 2005.

[39] S. Park, T. A. DiMaio, W. Liu, S. Wang, C. M. Sorenson, and N. Sheibani, "Endoglin regulates the activation and quiescence of endothelium by participating in canonical and non-canonical TGF- $\beta$ signaling pathways," Journal of Cell Science, vol. 126, no. 6, pp. 1392-1405, 2013.

[40] J.-M. Fan, N. G. Yee-Yung, P. A. Hill et al., "Transforming growth factor- $\beta$ regulates tubular epithelial-myofibroblast transdifferentiation in vitro," Kidney International, vol. 56, no. 4, pp. 1455-1467, 1999.
[41] T. Hayashida, M. Decaestecker, and H. W. Schnaper, "Crosstalk between ERK MAP kinase and Smad signaling pathways enhances TGF-beta-dependent responses in human mesangial cells," The FASEB Journal, vol. 17, no. 11, pp. 1576-1578, 2003.

[42] F. Strutz, M. Zeisberg, F. N. Ziyadeh et al., "Role of basic fibroblast growth factor-2 in epithelial-mesenchymal transformation," Kidney International, vol. 61, no. 5, pp. 1714-1728, 2002.

[43] I. Z. A. Pawluczyk and K. P. G. Harris, "Macrophages promote prosclerotic responses in cultured rat mesangial cells: a mechanism for the initiation of glomerulosclerosis," Journal of the American Society of Nephrology, vol. 8, no. 10, pp. 1525-1536, 1997.

[44] W. Kriz, M. Kretzler, M. Nagata et al., "A frequent pathway to glomerulosclerosis: deterioration of tuft architecturepodocyte damage-segmental sclerosis," Kidney and Blood Pressure Research, vol. 19, no. 5, pp. 245-253, 1996.

[45] A. Ljungquist, "The intrarenal arterial pattern in the normal and deseased human kidney," Acta Medica Scandinavica, vol. 174, supplement 401, pp. 5-34, 1963.

[46] D.-H. Kang, J. Kanellis, C. Hugo et al., "Role of the microvascular endothelium in progressive renal disease," Journal of the American Society of Nephrology, vol. 13, no. 3, pp. 806-816, 2002.

[47] J. T. Norman, I. M. Clark, and P. L. Garcia, "Hypoxia promotes fibrogenesis in human renal fibroblasts," Kidney International, vol. 58, no. 6, pp. 2351-2366, 2000.

[48] L. Renders and U. Heemann, "Chronic renal allograft damage after transplantation: what are the reasons, what can we do?" Current Opinion in Organ Transplantation, vol. 17, no. 6, pp. 634-639, 2012.

[49] A. Djamali and M. Samaniego, "Fibrogenesis in kidney transplantation: potential targets for prevention and therapy," Transplantation, vol. 88, no. 10, pp. 1149-1156, 2009.

[50] E. Song, H. Zou, Y. Yao et al., "Early application of MetRANTES ameliorates chronic allograft nephropathy," Kidney International, vol. 61, no. 2, pp. 676-685, 2002.

[51] J. Bedke, E. Kiss, L. Schaefer et al., "Beneficial effects of CCR1 blockade on the progression of chronic renal allograft damage," American Journal of Transplantation, vol. 7, no. 3, pp. 527-537, 2007.

[52] W. Land, H. Schneeberger, S. Schleibner et al., "The beneficial effect of human recombinant superoxide dismutase on acute and chronic rejection events in recipients of cadaveric renal transplants," Transplantation, vol. 57, no. 2, pp. 211-217, 1994.

[53] R. Pollak, J. H. Andrisevic, M. S. Maddux, S. A. Gruber, and M. S. Paller, "A randomized double-blind trial of the use of human recombinant superoxide dismutase in renal transplantation," Transplantation, vol. 55, no. 1, pp. 57-60, 1993.

[54] G. Nickenig and D. G. Harrison, "The AT1-type angiotensin receptor in oxidative stress and atherogenesis: part I: oxidative stress and atherogenesis," Circulation, vol. 105, no. 3, pp. 393396, 2002.

[55] T. Chabrashvili, C. Kitiyakara, J. Blau et al., "Effects of ANG II type 1 and 2 receptors on oxidative stress, renal NADPH oxidase, and SOD expression," American Journal of Physiology, vol. 285, no. 1, pp. R117-R124, 2003.

[56] M. Bhaskaran, K. Reddy, N. Radhakrishanan, N. Franki, G. Ding, and P. C. Singhal, "Angiotensin II induces apoptosis in renal proximal tubular cells," American Journal of Physiology, vol. 284, no. 5, pp. F955-F965, 2003.

[57] M. Burnier and A. Zanchi, "Blockade of the renin-angiotensinaldosterone system: a key therapeutic strategy to reduce renal 
and cardiovascular events in patients with diabetes," Journal of Hypertension, vol. 24, no. 1, pp. 11-25, 2006.

[58] G. Heinze, C. Mitterbauer, H. Regele et al., "Angiotensinconverting enzyme inhibitor or angiotensin II type 1 receptor antagonist therapy is associated with prolonged patient and graft survival after renal transplantation," Journal of the American Society of Nephrology, vol. 17, no. 3, pp. 889-899, 2006.

[59] S. Hiremath, D. Fergusson, S. Doucette, A. V. Mulay, and G. A. Knoll, "Renin angiotensin system blockade in kidney transplantation: a systematic review of the evidence," American Journal of Transplantation, vol. 7, no. 10, pp. 2350-2360, 2007.

[60] G. A. Knoll, M. Cantarovitch, E. Cole et al., "The Canadian ACE-inhibitor trial to improve renal outcomes and patient survival in kidney transplantation-study design," Nephrology Dialysis Transplantation, vol. 23, no. 1, pp. 354-358, 2008.

[61] R. B. Mannon, J. B. Kopp, P. Ruiz et al., "Chronic rejection of mouse kidney allografts," Kidney International, vol. 55, no. 5, pp. 1935-1944, 1999.

[62] A. K. Khanna, V. R. Cairns, C. G. Becker, and J. D. Hosenpud, "Transforming growth factor (TGF) $-\beta$ mimics and anti-TGF- $\beta$ antibody abrogates the in vivo effects of cyclosporine demonstration of a direct role of TGF- $\beta$ in immunosuppression and nephrotoxicity of cyclosporine," Transplantation, vol. 67, no. 6 , pp. 882-889, 1999.

[63] M. M. Shull, I. Ormsby, A. B. Kier et al., "Targeted disruption of the mouse transforming growth factor- $\beta 1$ gene results in multifocal inflammatory disease," Nature, vol. 359, no. 6397, pp. 693-699, 1992.

[64] M. Eikmans, Y. W. J. Sijpkens, H. J. Baelde, E. De Heer, L. C. Paul, and J. A. Bruijn, "High transforming growth factor- $\beta$ and extracellular matrix mRNA response in renal allografts during early acute rejection is associated with absence of chronic rejection," Transplantation, vol. 73, no. 4, pp. 573-579, 2002.

[65] F. S. Shihab, W. M. Bennett, H. Yi, and T. F. Andoh, "Pirfenidone treatment decreases transforming growth factor- $\beta 1$ and matrix proteins and ameliorates fibrosis in chronic cyclosporine nephrotoxicity," American Journal of Transplantation, vol. 2, no. 2, pp. 111-119, 2002.

[66] F. S. Shihab, W. M. Bennett, H. Yi, and T. F. Andoh, "Effect of pirfenidone on apoptosis-regulatory genes in chronic cyclosporine nephrotoxicity," Transplantation, vol. 79, no. 4, pp. 419-426, 2005.

[67] M. E. Cho, D. C. Smith, M. H. Branton, S. R. Penzak, and J. B. Kopp, "Pirfenidone slows renal function decline in patients with focal segmental glomerulosclerosis," Clinical Journal of the American Society of Nephrology, vol. 2, no. 5, pp. 906-913, 2007.

[68] M. H. J. Heeg, M. J. Koziolek, R. Vasko et al., "The antifibrotic effects of relaxin in human renal fibroblasts are mediated in part by inhibition of the Smad2 pathway," Kidney International, vol. 68, no. 1, pp. 96-109, 2005.

[69] C. S. Samuel, C. Zhao, R. A. D. Bathgate et al., "The relaxin geneknockout mouse: a model of progressive fibrosis," Annals of the New York Academy of Sciences, vol. 1041, pp. 173-181, 2005.

[70] S. L. Garber, Y. Mirochnik, C. S. Brecklin et al., "Relaxin decreases renal interstitial fibrosis and slows progression of renal disease," Kidney International, vol. 59, no. 3, pp. 876-882, 2001.

[71] L. Schaefer, K. Macakova, I. Raslik et al., "Absence of decorin adversely influences tubulointerstitial fibrosis of the obstructed kidney by enhanced apoptosis and increased inflammatory reaction," American Journal of Pathology, vol. 160, no. 3, pp. 11811191, 2002.
[72] W. A. Border, N. A. Noble, T. Yamamoto et al., "Natural inhibitor of transforming growth factor- $\beta$ protects against scarring in experimental kidney disease," Nature, vol. 360, no. 6402, pp. 361-364, 1992.

[73] T. Nakatani, S. Tanabe, Y.-S. Han et al., "Enhanced expression of endothelin-A receptor in human transplant renal arteriosclerosis," International Journal of Molecular Medicine, vol. 11, no. 2, pp. 153-156, 2003.

[74] S. R. Inman, W. K. Plott, R. A. Pomilee, J. A. Antonelli, and R. M. Lewis, "Endothelin-receptor blockade mitigates the adverse effect of preretrieval warm ischemia on posttransplantation renal function in rats," Transplantation, vol. 75, no. 10, pp. 1655$1659,2003$.

[75] J. M. Tikkanen, P. K. Koskinena, and K. B. Lemström, "Role of endogenous endothelin-1 in transplant obliterative airway disease in the rat," American Journal of Transplantation, vol. 4, no. 5, pp. 713-720, 2004.

[76] M. Zeisberg, J.-I. Hanai, H. Sugimoto et al., "BMP-7 counteracts TGF- $\beta 1$-induced epithelial-to-mesenchymal transition and reverses chronic renal injury," Nature Medicine, vol. 9, no. 7, pp. 964-968, 2003.

[77] G. R. Grotendorst, "Connective tissue growth factor: a mediator of TGf- $\beta$ action on fibroblasts," Cytokine and Growth Factor Reviews, vol. 8, no. 3, pp. 171-179, 1997.

[78] T. Q. Nguyen, P. Roestenberg, F. A. Van Nieuwenhoven et al., "CTGF inhibits BMP-7 signaling in diabetic nephropathy," Journal of the American Society of Nephrology, vol. 19, no. 11, pp. 2098-2107, 2008.

[79] O. Cheng, R. Thuillier, E. Sampson et al., "Connective tissue growth factor is a biomarker and mediator of kidney allograft fibrosis," American Journal of Transplantation, vol. 6, no. 10, pp. 2292-2306, 2006.

[80] G. H. Luo, Y. P. Lu, J. Song, L. Yang, Y. J. Shi, and Y. P. $\mathrm{Li}$, "Inhibition of connective tissue growth factor by small interfering RNA prevents renal fibrosis in rats undergoing chronic allograft nephropathy," Transplantation Proceedings, vol. 40, no. 7, pp. 2365-2369, 2008.

[81] S. Wakino, T. Kanda, and K. Hayashi, "Rho/Rho kinase as a potential target for the treatment of renal disease," Drug News and Perspectives, vol. 18, no. 10, pp. 639-643, 2005.

[82] M. Sato, Y. Muragaki, S. Saika, A. B. Roberts, and A. Ooshima, "Targeted disruption of TGF- $\beta 1 / \mathrm{Smad} 3$ signaling protects against renal tubulointerstitial fibrosis induced by unilateral ureteral obstruction," Journal of Clinical Investigation, vol. 112, no. 10, pp. 1486-1494, 2003.

[83] K. Nagatoya, T. Moriyama, N. Kawada et al., "Y-27632 prevents tubulointerstitial fibrosis in mouse kidneys with unilateral ureteral obstruction," Kidney International, vol. 61, no. 5, pp. 1684-1695, 2002.

[84] K. Ishimaru, H. Ueno, S. Kagitani, D. Takabayashi, M. Takata, and $\mathrm{H}$. Inoue, "Fasudil attenuates myocardial fibrosis in association with inhibition of monocyte/macrophage infiltration in the heart of DOCA/salt hypertensive rats," Journal of Cardiovascular Pharmacology, vol. 50, no. 2, pp. 187-194, 2007.

[85] T. Nakagawa, "Uncoupling of the VEGF-endothelial nitric oxide axis in diabetic nephropathy: an explanation for the paradoxical effects of VEGF in renal disease," American Journal of Physiology, vol. 292, no. 6, pp. F1665-F1672, 2007.

[86] B. H. Özdemir, F. N. Özdemir, N. Haberal, R. Emiroglu, B. Demirhan, and M. Haberal, "Vascular endothelial growth factor expression and cyclosporine toxicity in renal allograft 
rejection," American Journal of Transplantation, vol. 5, no. 4, pp. 766-774, 2005.

[87] S. Mizuno, K. Matsumoto, and T. Nakamura, "HGF as a renotrophic and anti-fibrotic regulator in chronic renal disease," Frontiers in Bioscience, vol. 13, no. 18, pp. 7072-7086, 2008.

[88] Y. Liu, "Hepatocyte growth factor in kidney fibrosis: therapeutic potential and mechanisms of action," American Journal of Physiology, vol. 287, no. 1, p. -F16, 2004.

[89] H. Azuma, S. Takahara, K. Matsumoto et al., "Hepatocyte growth factor prevents the development of chronic allograft nephropathy in rats," Journal of the American Society of Nephrology, vol. 12, no. 6, pp. 1280-1292, 2001.

[90] I. Herrero-Fresneda, J. Torras, M. Franquesa et al., "HGF gene therapy attenuates renal allograft scarring by preventing the profibrotic inflammatory-induced mechanisms," Kidney International, vol. 70, no. 2, pp. 265-274, 2006.

[91] S. Benvenuti and P. M. Comoglio, "The MET receptor tyrosine kinase in invasion and metastasis," Journal of Cellular Physiology, vol. 213, no. 2, pp. 316-325, 2007.

[92] T. Pihlajaniemi, R. Myllyla, and K. I. Kivirikko, "Prolyl 4hydroxylase and its role in collagen synthesis," Journal of Hepatology, vol. 13, no. 3, pp. S2-S7, 1991.

[93] N. Franceschini, O. Cheng, X. Zhang, P. Ruiz, and R. B. Mannon, "Inhibition of prolyl-4-hydroxylase ameliorates chronic rejection of mouse kidney allografts," American Journal of Transplantation, vol. 3, no. 4, pp. 396-402, 2003.

[94] K. A. Inkinen, A. P. Soots, L. A. Krogerus, I. T. Lautenschlager, and J. P. Ahonen, "Fibrosis and matrix metalloproteinases in rat renal allografts," Transplant International, vol. 18, no. 5, pp. 506512, 2005.

[95] J. Lutz, Y. Yao, E. Song et al., "Inhibition of matrix metalloproteinase during chronic allograft nephropathy in rats," Transplantation, vol. 79, no. 6, pp. 655-661, 2005.

[96] M. Kreutz, J. Fritsche, U. Ackermann, S. W. Krause, and R. Andreesen, "Retinoic acid inhibits monocyte to macrophage survival and differentiation," Blood, vol. 91, no. 12, pp. 47964802, 1998.

[97] J. Adams, E. Kiss, A. B. V. Arroyo et al., "13-cis retinoic acid inhibits development and progression of chronic allograft nephropathy," American Journal of Pathology, vol. 167, no. 1, pp. 285-298, 2005.

[98] C.-H. Heldin, U. Eriksson, and A. Östman, "New members of the platelet-derived growth factor family of mitogens," Archives of Biochemistry and Biophysics, vol. 398, no. 2, pp. 284-290, 2002.

[99] F. Eitner, T. Ostendorf, M. Kretzler et al., "PDGF-C expression in the developing and normal adult human kidney and in glomerular diseases," Journal of the American Society of Nephrology, vol. 14, no. 5, pp. 1145-1153, 2003.

[100] H. Iida, R. Seifert, C. E. Alpers et al., "Platelet-derived growth factor (PDGF) and PDGF receptor are induced in mesangial proliferative nephritis in the rat," Proceedings of the National Academy of Sciences of the United States of America, vol. 88, no. 15, pp. 6560-6564, 1991.

[101] M. Matsuda, K. Shikata, H. Makino et al., "Gene expression of PDGF and PDGF receptor in various forms of glomerulonephritis," American Journal of Nephrology, vol. 17, no. 1, pp. 25-31, 1997.

[102] G. Liu, S. Changsirikulchai, K. L. Hudkins et al., "Identification of platelet-derived growth factor D in human chronic allograft nephropathy," Human Pathology, vol. 39, no. 3, pp. 393-402, 2008.
[103] J. Savikko, E. Taskinen, and E. Von Willebrand, "Chronic allograft nephropathy is prevented by inhibition of plateletderived growth factor receptor: tyrosine kinase inhibitors as a potential therapy," Transplantation, vol. 75, no. 8, pp. 1147-1153, 2003.

[104] J. M. Rintala, J. Savikko, S. E. Rintala, and E. Von Willebrand, "FK778 ameliorates post-transplant expression of fibrogenic growth factors and development of chronic rejection changes in rat kidney allografts," Nephrology Dialysis Transplantation, vol. 23, no. 11, pp. 3446-3455, 2008.

[105] D. Gómez-Garre, R. Largo, N. Tejera, J. Fortes, F. Manzarbeitia, and J. Egido, "Activation of NF- $\kappa$ B in tubular epithelial cells of rats with intense proteinuria role of angiotensin II and endothelin-1," Hypertension, vol. 37, no. 4, pp. 1171-1178, 2001.

[106] N. Sakai, T. Wada, K. Furuichi et al., "Involvement of extracellular signal-regulated kinase and p38 in human diabetic nephropathy," American Journal of Kidney Diseases, vol. 45, no. 1, pp. 54-65, 2005.

[107] S. Tamada, T. Nakatani, T. Asai et al., "Inhibition of nuclear factor $-\kappa \mathrm{B}$ activation by pyrrolidine dithiocarbamate prevents chronic FK506 nephropathy," Kidney International, vol. 63, no. 1, pp. 306-314, 2003.

[108] Y. Yamamoto and R. B. Gaynor, “Therapeutic potential of inhibition of the NF- $\kappa$ B pathway in the treatment of inflammation and cancer," Journal of Clinical Investigation, vol. 107, no. 2, pp. 135-142, 2001.

[109] K. Tashiro, S. Tamada, N. Kuwabara et al., "Attenuation of renal fibrosis by proteasome inhibition in rat obstructive nephropathy: possible role of nuclear factor kappaB," International Journal of Molecular Medicine, vol. 12, no. 4, pp. 587-592, 2003.

[110] M. Andreucci, T. Faga, G. Lucisano et al., "Mycophenolic acid inhibits the phosphorylation of NF- $\kappa \mathrm{B}$ and JNKs and causes a decrease in IL-8 release in $\mathrm{H}_{2} \mathrm{O}_{2}$-treated human renal proximal tubular cells," Chemico-Biological Interactions, vol. 185, no. 3, pp. 253-262, 2010.

[111] J. Ashton-Chess, H. L. Mai, V. Jovanovic et al., "Immunoproteasome beta subunit 10 is increased in chronic antibody-mediated rejection," Kidney International, vol. 77, no. 10, pp. 880-890, 2010.

[112] N. Lachmann, M. Schütz, K. Budde, C. Schönemann, and J. Waiser, "Antihumoral rejection therapy by proteasome inhibitor bortezomib: a case series," Clinical Transplants, pp. 351-358, 2009.

[113] J. Ho, D. N. Rush, I. W. Gibson et al., "Early urinary CCL2 is associated with the later development of interstitial fibrosis and tubular atrophy in renal allografts," Transplantation, vol. 90, no. 4, pp. 394-400, 2010.

[114] S. M. Kurian, R. Heilman, T. S. Mondala et al., "Biomarkers for early and late stage chronic allograft nephropathy by proteogenomic profiling of peripheral blood," PLOS ONE, vol. 4, no. 7, Article ID e6212, 2009.

[115] R. Tetaz, C. Trocmé, M. Roustit et al., "Predictive diagnostic of chronic allograft dysfunction using urinary proteomics analysis," Annals of Transplantation, vol. 17, no. 3, pp. 52-60, 2012.

[116] A. Scherer, A. Krause, J. R. Walker, A. Korn, D. Niese, and F. Raulf, "Early prognosis of the development of renal chronic allograft rejection by gene expression profiling of human protocol biopsies," Transplantation, vol. 75, no. 8, pp. 1323-1330, 2003.

[117] A. Scherer, W. Gwinner, M. Mengel et al., "Transcriptome changes in renal allograft protocol biopsies at 3 months precede 
the onset of interstitial fibrosistubular atrophy (IFTA) at 6 months," Nephrology Dialysis Transplantation, vol. 24, no. 8, pp. 2567-2575, 2009.

[118] G. Einecke, J. Reeve, B. Sis et al., "A molecular classifier for predicting future graft loss in late kidney transplant biopsies," Journal of Clinical Investigation, vol. 120, no. 6, pp. 1862-1872, 2010.

[119] W. S. Oetting, W. Guan, D. P. Schladt et al., "Telomere length of recipients and living kidney donors and chronic graft dysfunction in kidney transplants," Transplantation, vol. 97, no. 3, pp. 325-329, 2014.

[120] D. G. Maluf, C. I. Dumur, J. L. Suh et al., "Evaluation of molecular profiles in calcineurin inhibitor toxicity post-kidney transplant: input to chronic allograft dysfunction," American Journal of Transplantation, vol. 14, no. 5, pp. 1152-1163, 2014.

[121] J. K. Walker, R. R. Alloway, P. Roy-Chaudhury et al., "A prospective trial of a steroid-free/calcineurin inhibitor minimization regimen in human leukocyte antigen (HLA)-identical live donor renal transplantation," Transplantation, vol. 87, no. 3 , pp. 408-414, 2009.

[122] W. Fadili, M. Habib Allah, and I. Laouad, "Chronic renal allograft dysfunction: risk factors, immunology and prevention," Arab Journal of Nephrology and Transplantation, vol. 6, no. 1, pp. 45-50, 2013.

[123] F. P. Schena, M. D. Pascoe, J. Alberu et al., "Conversion from calcineurin inhibitors to sirolimus maintenance therapy in renal allograft recipients: 24-month efficacy and safety results from the CONVERT trial," Transplantation, vol. 87, no. 2, pp. 233242, 2009.

[124] L. Luo, Z. Sun, and G. Luo, "Rapamycin is less fibrogenic than Cyclosporin A as demonstrated in a rat model of chronic allograft nephropathy," Journal of Surgical Research, vol. 179, no. 1, pp. E255-E263, 2013.

[125] G. A. Böhmig, H. Regele, and W. H. Hörl, "Protocol biopsies after kidney transplantation," Transplant International, vol. 18, no. 2, pp. 131-139, 2005.

[126] L. C. Paul, "New insights in chronic allograft rejection," Current Opinion in Urology, vol. 12, no. 2, pp. 89-93, 2002.

[127] B. M. Shrestha and J. L. Haylor, "Factors influencing long-term outcomes following renal transplantation: a review," Journal of the Nepal Medical Association, vol. 46, no. 167, pp. 136-142, 2007.

[128] H. Khan, M. Mubarak, T. Aziz et al., "Prevalence and risk factors for early chronic allograft nephropathy in a live related renal transplant program," Journal of Nephropathology, vol. 3, no. 2, pp. 69-79, 2014. 


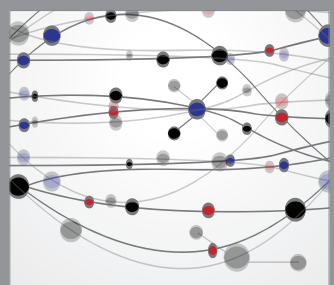

The Scientific World Journal
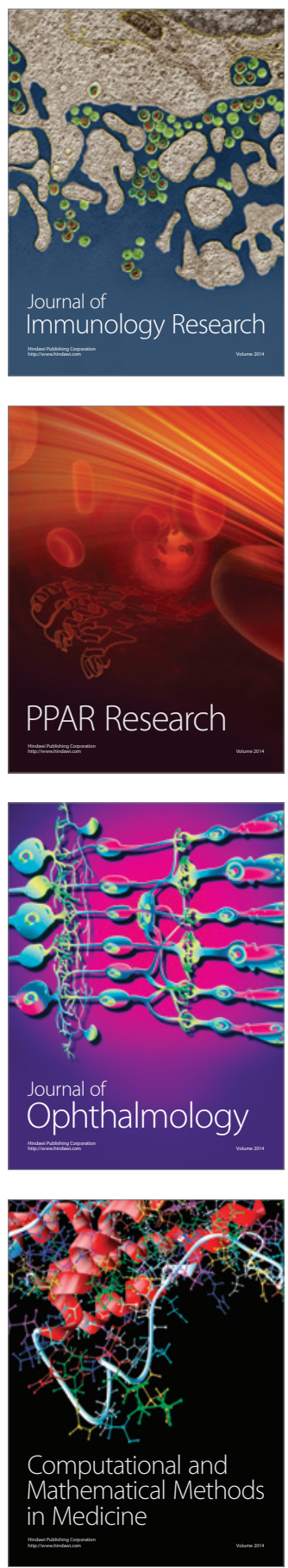

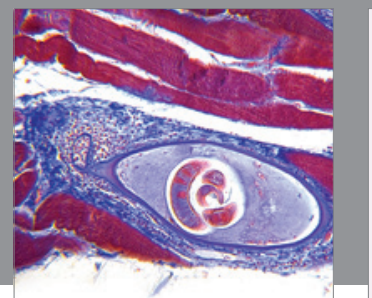

Gastroenterology

Research and Practice
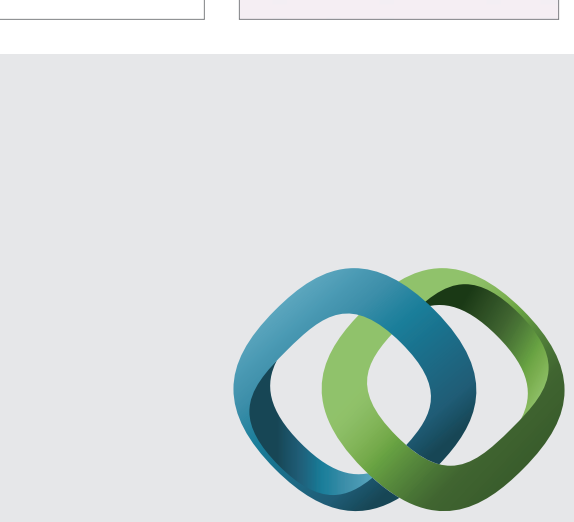

\section{Hindawi}

Submit your manuscripts at

http://www.hindawi.com
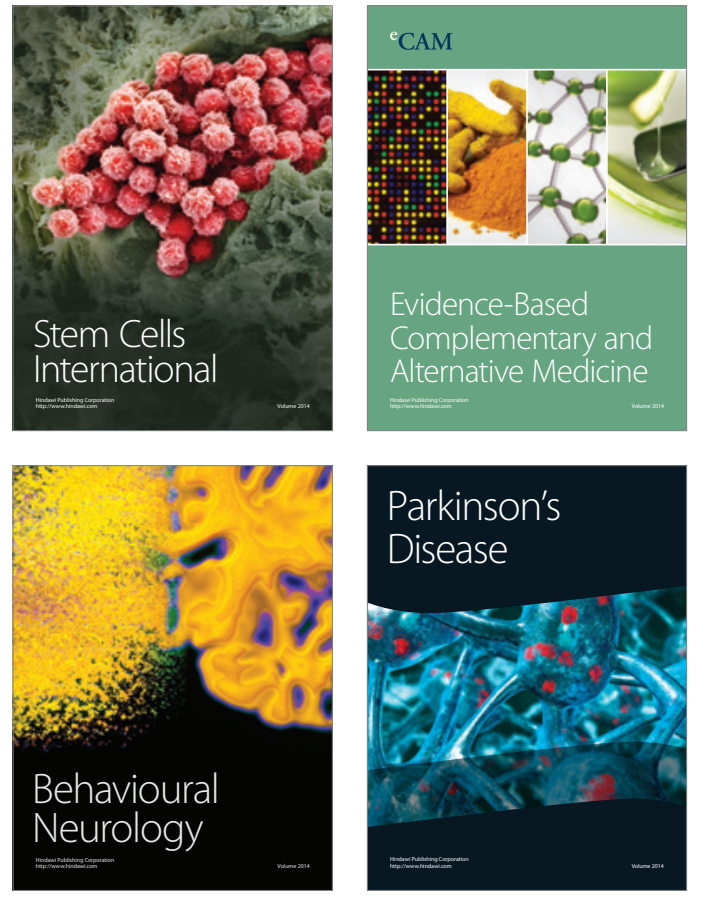
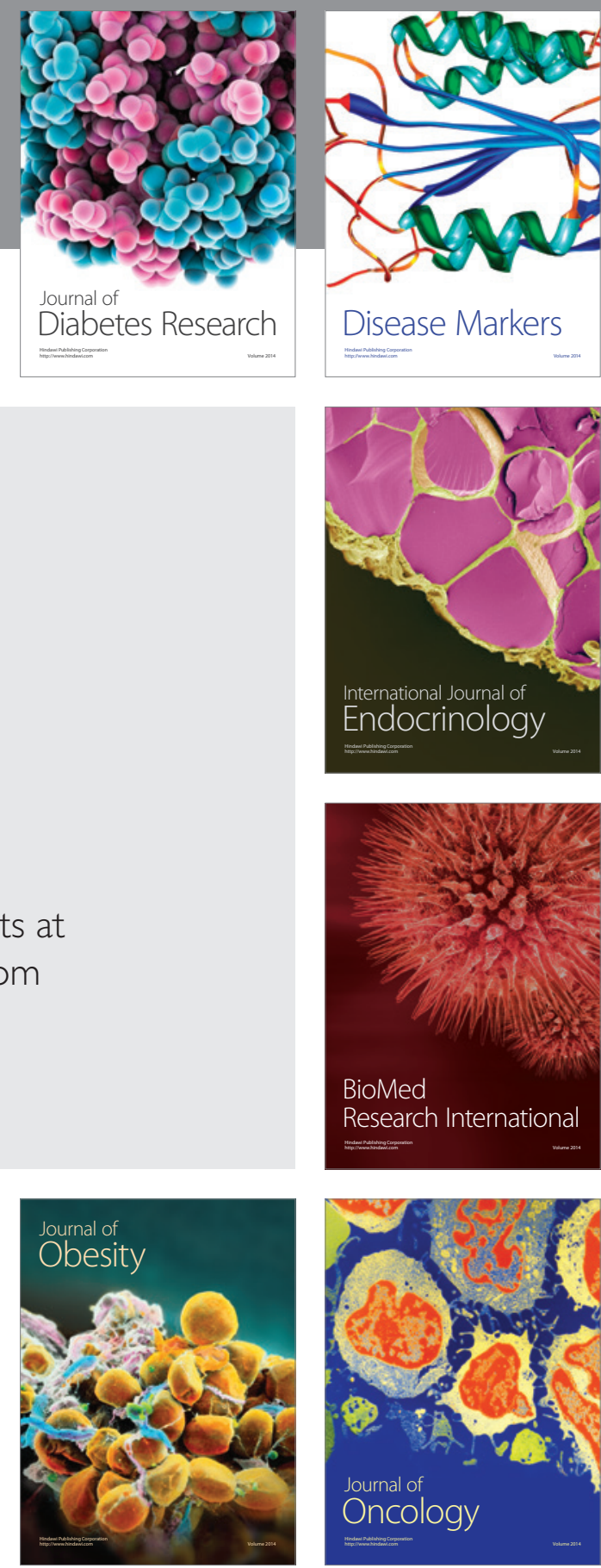

Disease Markers
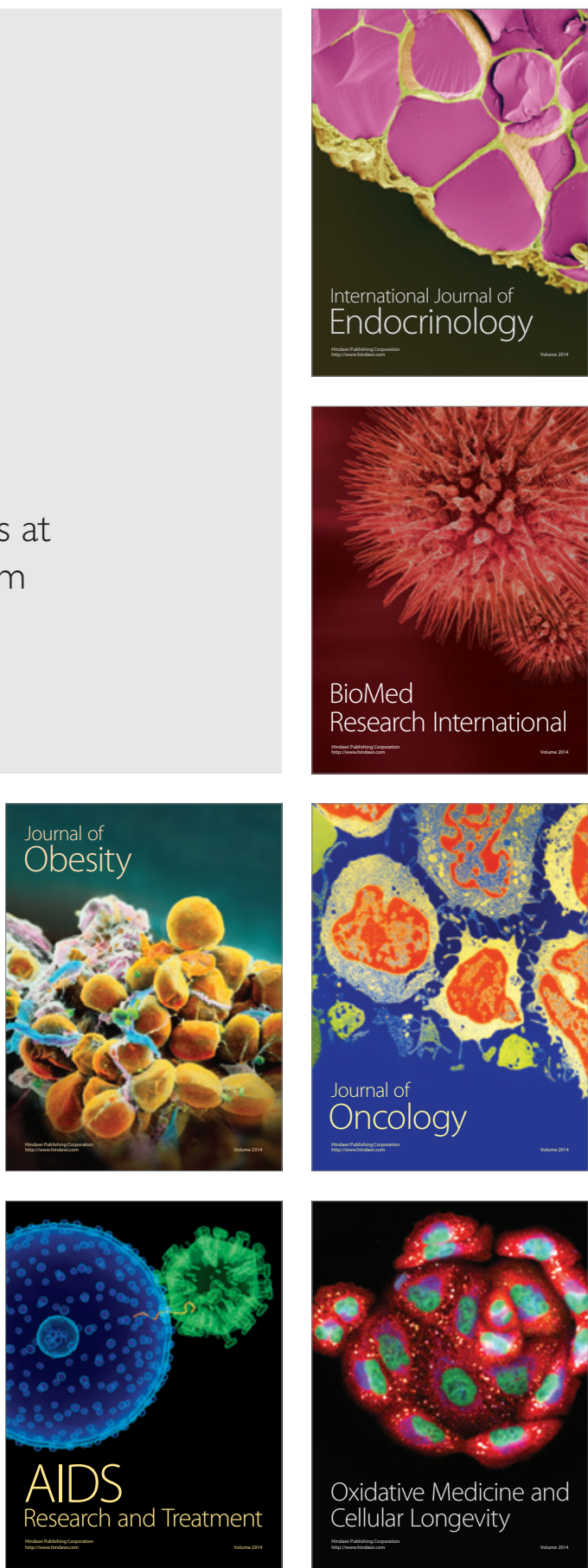